\title{
Beneficial Effects of Apple Vinegar on Hyperglycemia and Hyperlipidemia in Hypercaloric-Fed Rats
}

\author{
Driss Ousaaid (D), Hassan Laaroussi $\left(\mathbb{D}\right.$, Meryem Bakour $\left(\mathbb{D}\right.$, Asmae ElGhouizi ${ }^{D}$, \\ Abderrazak Aboulghazi, Badiaa Lyoussi $\odot$, and Ilham ElArabi \\ Laboratory of Natural Substances, Pharmacology, Environment, Modeling, Health and Quality of Life (SNAMOPEQ), Faculty of \\ Sciences Dhar El Mahraz, University Sidi Mohamed Ben Abdellah, Fez, Morocco \\ Correspondence should be addressed to Driss Ousaaid; driss.ousaaid@usmba.ac.ma
}

Received 5 February 2020; Revised 17 June 2020; Accepted 2 July 2020; Published 13 July 2020

Academic Editor: Virginia Boccardi

Copyright ( 2020 Driss Ousaaid et al. This is an open access article distributed under the Creative Commons Attribution License, which permits unrestricted use, distribution, and reproduction in any medium, provided the original work is properly cited.

\begin{abstract}
The main objective of this study is to determine the effects of apple vinegar on the metabolic changes caused by hypercaloric diet in Wistar rats. Apple vinegar was first analyzed to find out the total acidity, the polyphenolic and flavonoid contents, the total antioxidant capacity, and the free radical scavenging activity. In vivo study on adult male and female Wistar rats was conducted by administering a drink containing either $10 \% \mathrm{D}$-glucose or water (control) for five weeks. Apple vinegar is administered daily by gavage $(2 \mathrm{~mL} / \mathrm{kg})$ to rats fed D-glucose for 5 weeks. The results showed that the polyphenolic content in apple vinegar was $148.02 \pm 10.16 \mathrm{mg} \mathrm{GAE} / 100 \mathrm{~mL}$, flavonoid content was $22.93 \pm 0.73 \mathrm{QE} / 100 \mathrm{~mL}$, and total antioxidant capacity was $13.4 \pm 0.47$ mg AAE $/ 100 \mathrm{~mL}$. Free radical $\mathrm{IC}_{50}$ apple vinegar scavenging activity $(\mathrm{DPPH})$ was $0.74 \pm 0.154 \mu \mathrm{L} / \mathrm{mL}$. The total acidity was $(3.24 \pm 0.02 \mathrm{mg} \mathrm{AAE} / 100 \mathrm{~mL})$. The treatment during five weeks with D-glucose leads to increased plasma glucose, lipid profile, hepatic enzyme levels, urea, and creatinine. Simultaneous treatment with apple vinegar improves the parameters studied. These results clearly show that the daily consumption of vinegar can reduce the rise in blood sugar and lipid profile induced by hypercaloric diet in rats. Therefore, the use of apple vinegar would have a very beneficial effect in the prevention of metabolic disorders caused by high-caloric food.
\end{abstract}

\section{Introduction}

Traditionally, the role of diet has been to provide the energy and essential nutrients to support different physiological functions of the body. However, over the years, the role of diet has changed; food is increasingly called upon to provide physiological benefits in terms of management and disease prevention [1]. The changes in lifestyle food (fast food, increased caloric consumption, stored food, and physical inactivity), among others, are key elements facilitating the installation of the metabolic disorders and the onset of many pathologies. Our current feeding is therefore represented by significant carbohydrate contributions. The increase in sugar consumption is related to the accentuation in the prevalence of obesity and insulin resistance predisposing to type 2 diabetes [2].
The hypercaloric diet (HCD) is the principal factor which causes the development of metabolic risk factor of cardiovascular diseases, hypercholesterolemia, hypertension, hyperglycemia, type 2 diabetes, and some cancer types [3-5]. Investigations have shown that chronic glucose feeding induces hypertension, insulin resistance, hyperglycemia, and higher vascular oxidative stress [6-9].

Hyperglycemia is often associated with serious complications such as lipid profile alteration, insulin resistance, liver toxicity, renal dysfunction, retinopathy, and cardiovascular diseases $[10,11]$. Effective methods to reduce the onset of diabetes include the control of postprandial hyperglycemia, hyperlipidemia, and the inhibition of lipid and carbohydrate hydrolyzing enzymes [12]. This hyperglycemia represents a key factor for the development of oxidative stress and reactive oxygen species (ROS) [13]. 
Oxidative stress is at origin of several pathologies such as diabetes. Secondary metabolites contained in natural products such as apple vinegar would be a powerful antioxidant to prevent oxidative stress [14].

There is a need to find alternative solutions to reduce the risk, spread, and progression of metabolic diseases. Several studies have been focused on the identification of alternative therapies to decrease disease incidence, in particular disaccharidase inhibitors and alpha-glucosidase inhibitor $[15,16]$.

Apple vinegar is widely used and appreciated by the Moroccan population and around the world. Several studies clearly demonstrated many benefits of vinegar consumption such as glucose-lowering effect in patient with glucose abnormalities [16-18], improved insulin sensitivity in insulinresistant patients [19], decreasing the glycemic index of carbohydrate food for people with and without diabetes [19], antihyperlipidemic [18], hepatoprotective effect [20, 21 ], and modulation of lipid peroxidation [22].

Since there has been no study on the therapeutic effect of the apple vinegar on glycemic induced by a high carbohydrate diet, this work was conducted to determine whether a subchronic treatment during five weeks with apple vinegar would have a potential effect with regard to the modulation of hyperglycemia and hyperlipidemia in HCD-fed rats.

\section{Materials and Methods}

2.1. Vinegar Sample. Apple vinegar was purchased from a

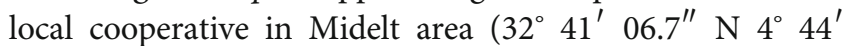
$\left.42.4^{\prime \prime} \mathrm{W}\right)$. The raw material used to produce this vinegar is made from two varieties of apple (Golden delicious and Starking delicious). The sample was kept in the fridge $\left(3^{\circ} \mathrm{C}\right)$ until it was used for the various experiments carried out in this work.

2.2. The Antioxidant Contents and Activities of Apple Vinegar. The total polyphenolic content in the apple vinegar sample was determined by Folin-Ciocalteu reagent using a method described by Singleton et al. [23]; the value of total polyphenolic compounds was expressed as milligrams of gallic acid equivalent per $100 \mathrm{~mL}$ of vinegar. Total flavonoid content was determined using the method described by Kong et al. [24]; the outcome was expressed as milligrams of quercetin equivalent per $100 \mathrm{~mL}$ of vinegar.

The total antioxidant capacity of apple vinegar was examined using the method reported by Zengin et al. [25]. The result was expressed as milligrams of ascorbic acid equivalent per $100 \mathrm{~mL}$ of vinegar. The scavenging activity of apple vinegar for the radical 2,2-diphenyl-1-picrylhydrazyl (DPPH) was measured as described by Miguel et al. and Laaroussi et al. $[26,27]$. The scavenging activity was estimated based on the percentage of DPPH radical scavenged using the following equation:

$$
\text { \%Inhibition }=\left(A_{0}-A_{1} / A_{0} \times 100\right.
$$

$A_{0}$ is the absorbance of the control; $A_{1}$ is the absorbance of the sample.
The $\mathrm{IC}_{50} \mathrm{DPPH}$ was calculated from the obtained graph of inhibition percentage of radical DPPH.

2.3. Total Acidity of Apple Vinegar. The total acidity was determined by titration according to the French standard [28].

2.4. Animals and Procedures. Adult male and female rats weighing between $168.5 \pm 8.5 \mathrm{~g}$ and $132 \pm 8 \mathrm{~g}$, respectively, were obtained from animal house breeding center, Faculty of Sciences, Dhar Al-Mahraz Fez, and were housed under normal environmental conditions $\left(25 \pm 1^{\circ} \mathrm{C}\right) \quad(55 \pm 5 \%$ humidity on a 12-hour light-dark cycle). The care and handling of the animals were in accordance with the internationally accepted standard guidelines for the use of animals, and the protocol was approved by the institutional committee on animal care following the French Technical Specifications for the Production, Care and Use of the Laboratory Animals.

The rats were randomly allocated into three groups of eight rats each ( 4 females, 4 males) treated for 5 weeks as follows: group 1: represents the control group, had free access to tap water only and normal diet; group 2: had free access to drinking solution of $10 \% \mathrm{D}$-glucose and to a normal diet; and group 3: had free access to $10 \% \mathrm{D}$-glucose and treated daily by gavage with apple vinegar $(2 \mathrm{~mL} / \mathrm{kg})$. The body weight was measured in the first and the last day of treatment.

After 5 weeks of treatment, the rats were fasted overnight $(16 \mathrm{~h})$ and sacrificed by decapitation after light ethyl urethane anesthesia. Blood was withdrawn from each rat, and plasma was recovered for various biochemical determinations.

2.5. Biochemical Methods. The plasma was immediately separated by low-speed centrifugation at $1500 \times \mathrm{g}$ for $15 \mathrm{~min}$. Plasma was obtained to analyze blood glucose, total cholesterol (TC), triglycerides (TG), and high-density lipoprotein cholesterol (HDL-C) and LDL cholesterol (LDL-C), total protein, alanine aminotransferase (ALT), aspartate aminotransferase (AST), lactate dehydrogenase (LDH), serum creatinine, urea, calcium $\left(\mathrm{Ca}^{2+}\right)$, sodium $\left(\mathrm{Na}^{+}\right)$, potassium $\left(\mathrm{K}^{+}\right)$, and chloride $\left(\mathrm{Cl}^{-}\right)$.

2.6. Statistical Analysis. The data were expressed asmean \pm SDvariable reading in each group. Statistical comparisons between the groups were performed with one-way analysis of variance (ANOVA) followed by Dunnett test to compare all columns with control column (GraphPad Prism 5 software). The data followed normal distribution.

\section{Results}

3.1. Total Polyphenolic Content (TPC), Total Flavonoid Content (TFC), Antioxidant Activities (DPPH and TAC), and Total Acidity (TA) of Apple Vinegar. TPC, TFC, TA, TAC, and DPPH $\left(\mathrm{IC}_{50}\right)$ values of apple vinegar are shown in Table 1. Generally, the total polyphenolic content was $148.02 \pm 10.16 \mathrm{mg} \mathrm{GAE} / 100 \mathrm{~mL}$, flavonoids was $22.93 \pm$ $0.73 \mathrm{QE} / 100 \mathrm{~mL}$, and total antioxidant activity was $13.4 \pm$ $0.47 \mathrm{mg}$ AAE $/ 100 \mathrm{~mL}$. The $\mathrm{IC}_{50}$ of free radical scavenging activity of apple vinegar $(\mathrm{DPPH})$ was $(0.74 \pm 0.154 \mu \mathrm{L} / \mathrm{mL})$. 
TABLE 1: Total acidity, antioxidant contents, and antioxidant activities of apple vinegar.

\begin{tabular}{cccccc}
\hline & TPC $(\mathrm{mg} \mathrm{GAE} / 100 \mathrm{~mL})$ & $\mathrm{TFC}(\mathrm{mg} \mathrm{QE} / 100 \mathrm{~mL})$ & $\mathrm{TAC}(\mathrm{mg} \mathrm{AAE} / 100 \mathrm{~mL})$ & $\mathrm{IC}_{50} \mathrm{DPPH}(\mu \mathrm{L} / \mathrm{mL})$ & $\mathrm{TA}(\mathrm{mg} \mathrm{AAE} / 100 \mathrm{~mL})$ \\
\hline Apple vinegar & $148.02 \pm 10.16$ & $22.93 \pm 0.73$ & $13.4 \pm 0.47$ & $0.74 \pm 0.154$ & $3.24 \pm 0.02$ \\
\hline
\end{tabular}

The total acidity was demonstrated by milligrams of acetic acid equivalent per $100 \mathrm{~mL}$ of vinegar $(3.24 \pm 0.02 \mathrm{mg}$ $\mathrm{AAE} / 100 \mathrm{~mL}$ ).

\subsection{Biological Assessments}

3.2.1. Effect of D-Glucose and Apple Vinegar on Body Weight and Body Weight Gain. Table 2 resumes the change in body weight of rats in the experimental groups. The body weight gain was not significantly modified either by $\mathrm{D}$-glucose feeding or by apple vinegar despite a trend to a diminution of body weight gain in both sexes (males and females), which was observed with apple vinegar treatment (group 3).

\subsubsection{Effect of D-Glucose and Apple Vinegar on Glycemia.} Figure 1 shows that five weeks of treatment with $\mathrm{D}$-glucose caused a significant increase in blood glucose level $(p<0.05$ ) $(8.27 \pm 0.12 \mathrm{mmol} / \mathrm{L}$ and $10.06 \pm 0.46 \mathrm{mmol} / \mathrm{L}$ in male and female rats, respectively) in comparison to control $(5.08 \pm 0.11 \mathrm{mmol} / \mathrm{L}$ and $5.06 \pm 0.23 \mathrm{mmol} / \mathrm{L}$ in males and females, respectively) and rats treated by $\mathrm{D}$-glucose combined with apple vinegar $(5.09 \pm 0.42 \mathrm{mmol} / \mathrm{L}$ and $5.44 \pm$ $0.15 \mathrm{mmol} / \mathrm{L}$ for male and female rats, respectively).

\subsubsection{Effect of D-Glucose and Apple Vinegar on Plasma Lipid} Profile. Table 3 shows concentrations of the serum which was collected in the three groups of rats of our experiment, in total cholesterol (TC), in triglycerides (TG), in low-density lipoproteins (LDL-C), or in high-density lipoproteins (HDL-C).

In group 2 which underwent a subchronic D-glucose supply, the LDL-C concentration increased significantly in rats of both sexes, the TC increased significantly in female rats, while no significant increase was observed in TG levels. On the other hand, the HDL-C concentration decreased significantly $(p<0.05)$ in rats of both sexes. In group 3, apple vinegar supplemented with $\mathrm{D}$-glucose made it possible to reduce the serum concentrations of LDL-C, TG, and TC but not statistically significant.

\subsubsection{Effect of D-Glucose and Apple Vinegar on Hepatic} Enzymes. The effect of D-glucose intake and apple vinegar (AV) coadministration on hepatic enzymes in different groups is summarized in Table 3. D-Glucose increased significantly the levels of plasma aspartate aminotransferase (AST) $(p<0.05)$ and LDH $(p<0.05)$ in both sexes but not significantly increased ALT of both sexes compared with the other groups. The levels of plasma urea were found to be significantly $(p<0.05)$ increased but not significantly concerning creatinine in the D-glucose-fed group when compared to the control group and D-glucose combined with apple vinegar-treated group.
3.2.5. Effect of D-Glucose and Apple Vinegar on Kidney Indices of Toxicity. In group 2 of rats fed D-glucose for 5 weeks, there are no significant changes in the plasma total protein concentrations but there is a slight increase in creatinine levels compared to the control group; on the other hand, there is a significant increase in urea levels. The addition of apple vinegar to group 3 causes a significant decrease in urea levels and a slight decrease in creatinine levels. We also note, in the same group, a certain increase in the levels of total proteins (Table 3 ).

3.2.6. Effect of D-Glucose and Apple Vinegar on Plasma Electrolytes. In an attempt to evaluate the effect of subchronic D-glucose administration and apple vinegar supplementation on plasma electrolytes, we have measured the plasma levels of calcium $\left(\mathrm{Ca}^{2+}\right)$, sodium $\left(\mathrm{Na}^{+}\right)$, potassium $\left(\mathrm{K}^{+}\right)$, and chloride $\left(\mathrm{Cl}^{-}\right)$in rats of different groups. Results are summarized in Table 3. It was clearly shown that the plasma sodium and chloride levels were not significantly changed either by D-glucose feeding alone or combined with apple vinegar in comparison with the control group. The plasma potassium levels in both sexes of group 2 were not changed significantly. The coadministration of $\mathrm{D}$-glucose and apple vinegar $(\mathrm{AV})$ decreased significantly $(p<0.05)$ the plasma potassium levels in rats of both sexes. Concerning plasmatic calcium levels, the D-glucose intake ( $10 \%$ in water) for 5 weeks as well as the simultaneous administration of Dglucose and apple vinegar $(2 \mathrm{~mL} / \mathrm{kg})$ increased significantly $(p<0.05)$ the calcium levels as compared to the nondiabetic group in male and female rats (group 1). In addition, a significant difference was observed between male rats of group 3 and both sexes of group 2 .

\section{Discussion}

Apple vinegar is very well known for its unsuspected health benefits; it is rich in bioactive molecules such as polyphenolic compounds known for its several therapeutic effects [29]. The current study showed that five-week treatment with Dglucose increased glycemia, hepatic enzymes, and lipid profile levels; these results are in agreement with previous studies $[9,30,31]$. Furthermore, subchronic feeding with D-glucose combined with apple vinegar modulates the different studied parameters. Importantly, until now, there are no studies that have been conducted to determine the efficacy of apple vinegar on hyperglycemia and hyperlipidemia caused by $\mathrm{D}$-glucose feeding in rats of both sexes.

Decreasing postprandial hyperglycemia is a therapeutic way, which delays glucose absorption [32]. Previously, there are many authors who reported that the apple vinegar can play an important role in food digestion. Additionally, in prophetic medicine, the Prophet Mohammed peace be upon him recommended drinking vinegar in the prophetic 
TABLE 2: Effect of D-glucose and apple vinegar on body weight and body weight gain.

\begin{tabular}{lcccccc}
\hline & & \multicolumn{2}{c}{ Body weight $(\mathrm{g})$} & \multicolumn{2}{c}{ Body weight gain (g) } \\
Groups & Males & Females & Males & Females & Males & Females \\
\hline Group 1 & $175.5 \pm 2.12$ & $126 \pm 2.82$ & $195.5 \pm 3.53$ & $141.5 \pm 0.70$ & $20 \pm 5.65$ & $15.5 \pm 2.12$ \\
Group 2 & $168.5 \pm 2.12$ & $128 \pm 5.65$ & $200.5 \pm 10.60$ & $147.5 \pm 17.67$ & $32 \pm 8.48$ & $19.5 \pm 12.02$ \\
Group 3 & $172 \pm 2.82$ & $126 \pm 2.82$ & $185.5 \pm 6.36$ & $138 \pm 5.65$ & $13.5 \pm 3.53$ & $12 \pm 8.48$ \\
\hline
\end{tabular}

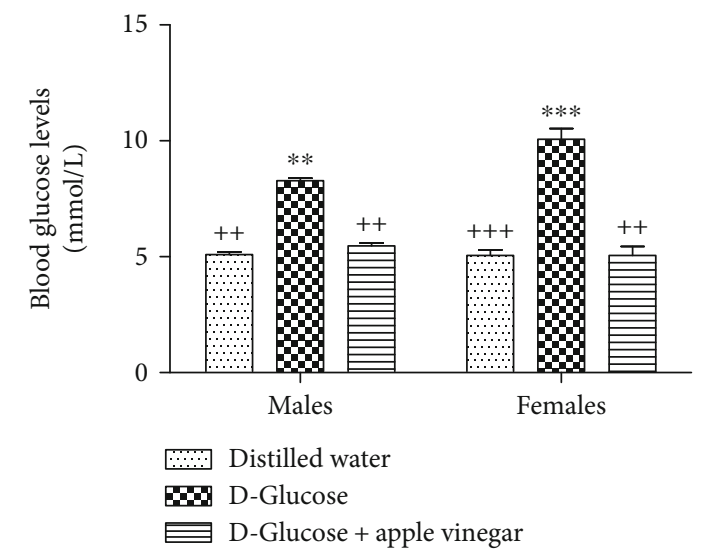

FIgURE 1: Effect of D-glucose and apple vinegar on the blood glucose levels in experimental animals. ${ }^{*} p<0.05$ vs. the distilled water group. ${ }^{+} p<0.05$ vs. the $\mathrm{D}$-glucose group.

hadeeth: "vinegar is the best edible." Moreover, the apple vinegar has been shown to reduce fasting blood glucose $[16,19$, 33-35], by reducing the post-prandial insulin response [35]. The intake of apple vinegar ameliorates the insulin sensitivity and increase the uptake of glucose in the skeletal muscles [17]. Acetic acid (a major component of vinegar) was suggested as a key to slowing down of gastric emptying [34] and decreasing of disaccharidase activity in the small intestinal [15], intestine maltase, lactase, and sucrose activities [18]. Additionally, it promotes the uptake of glucose by muscle performance $[17,36]$, consequently, decreasing fasting blood glucose.

The finding results revealed that apple vinegar was able to reduce moderately the concentration of total cholesterol (TC) in female rats as well as triglycerides and low-density lipoprotein cholesterol (LDL-C) in rats of both sexes. In opposite, it increased the level of high-density lipoprotein cholesterol (HDL-C) in male and female rats.

Data are in agreement with previous studies which have shown that the apple vinegar modulates the lipid profile $[37,38]$. The regulation of lipids has an effect on weight loss; nowadays, many studies have shown that the apple vinegar promotes antiobesity effects [22] and exerts its beneficial effects via scavenging free radicals $[22,39]$. Our data showed that the treatment with apple vinegar modulates the weight gain in both sexes compared with group of rats treated with D-glucose.

In the present study, the supplementation of apple vinegar to the HCD decreases the hepatic enzyme levels. It could be due to their high content of bioactive molecules such as polyphenolic compounds [39].

The results of antioxidant contents obtained in apple vinegar are in accordance with those reported by previous reports $[39,40]$. The richness of vinegar in bioactive molecules such as polyphenols and flavonoids depends mainly on raw matter [41].

Regarding the liver function, the subchronic administration of D-glucose induced a high increase of plasmatic AST and LDH levels in male and female rats which are in accordance with the findings of Goboza et al. [42]. The increase of plasma hepatic enzymes is a major index of liver damage and hepatic cell necrosis which causes molecular destabilization of membrane cell phospholipids and thus the leakage of cytoplasmic enzymes [43]. It was found that HCD induces metabolic disorders and oxidative stress with serious hepatocyte injury surpassing antioxidant defense systems [40].

Oxidative stress is the main cause of many liver problems; therefore, the attenuation of reactive oxygen species (ROS) caused by HCD is the effective approach to prevent the extent of liver damage. Indeed, the simultaneous administration of D-glucose and apple vinegar (group 3) for five weeks reduced significantly the plasma levels of AST and LDH as compared to nontreated diabetic rats (group 2). These results were in agreement with previous studies [16, 20]. Furthermore, our data indicate that D-glucose administrated alone has no significant effect on the normal serum levels of ALT. The protective effect of apple vinegar might be due to its richness in various chemical components and bioactive molecules [44].

In addition, the administration of apple vinegar has been reported to decrease lipid peroxidation in ovariectomized mice, promotes GSH-Px activity which can prevent oxidative stress [22], and promotes the enzymatic antioxidant defense systems [21].

The evaluation of plasma electrolytes such as $\left(\mathrm{Ca}^{+}, \mathrm{Na}^{+}\right.$, and $\mathrm{K}^{+}$) is a crucial step in the diagnosis of metabolic disorders, in particular type 2 diabetes (T2D), because they play a key role in the regulation of blood pressure [45]. Sodium is an electrolyte mainly involved in the development of high blood pressure (hypertension) and other cardiovascular complications. The hypokalemia expressed by diabetic rats cotreated with apple vinegar (group 3) may be due to a compensatory response from the renal system to moderate the concentration of $\mathrm{Na}^{+}$and thus maintain the balance of blood sodium [46].

Furthermore, the present study revealed a significant increase in plasma calcium concentrations in nontreated diabetic rats as compared to the control group. In fact, numerous studies have been reported that the high plasma 
TABLE 3: Effect of D-glucose and apple vinegar on plasma lipid profile, liver function, kidney indices of toxicity, and plasma mineral element status.

\begin{tabular}{|c|c|c|c|c|c|c|}
\hline \multirow{2}{*}{ Biochemical parameters } & \multicolumn{2}{|c|}{ Group 1} & \multicolumn{2}{|c|}{ Group 2} & \multicolumn{2}{|c|}{ Group 3} \\
\hline & Males & Females & Males & Females & Males & Females \\
\hline \multicolumn{7}{|c|}{ Plasma lipid profile } \\
\hline $\mathrm{TC}(\mathrm{mg} / \mathrm{dL})$ & $42.5 \pm 3.53$ & $44 \pm 1.41$ & $55 \pm 14.14$ & $73.5 \pm 2.12^{*}$ & $60 \pm 5.65$ & $60 \pm 4.24$ \\
\hline $\mathrm{TG}(\mathrm{mg} / \mathrm{dL})$ & $54.5 \pm 13.43$ & $43.5 \pm 2.12$ & $73 \pm 2.82$ & $60 \pm 15.55$ & $48 \pm 1.41$ & $36 \pm 11.31$ \\
\hline HDL-c (mg/dL) & $0.24 \pm 0.4$ & $0.21 \pm 0.15$ & $0.14 \pm 0.01^{*}$ & $0.14 \pm 0.05^{*}$ & $0.21 \pm 0.01$ & $0.15 \pm 0.005$ \\
\hline LDL-c (mg/dl) & $42.5 \pm 0.70$ & $44.5 \pm 2.12$ & $55.5 \pm 4.94^{*}$ & $52.5 \pm 2.12^{*}$ & $47 \pm 1.41$ & $46.5 \pm 2.12$ \\
\hline \multicolumn{7}{|c|}{ Liver function } \\
\hline AST (U/L) & $109.5 \pm 3.53^{+}$ & $119 \pm 1.41$ & $159.5 \pm 7.77^{*}$ & $174 \pm 15.55^{*}$ & $93.5 \pm 7.77^{+}$ & $129 \pm 12.79$ \\
\hline $\operatorname{ALT}(\mathrm{U} / \mathrm{L})$ & $35 \pm 2.82$ & $20.5 \pm 10.60$ & $42.5 \pm 3.53$ & $50 \pm 2.82$ & $17.5 \pm 2.12^{*+}$ & $20 \pm 9.89$ \\
\hline $\mathrm{LDH}(\mathrm{U} / \mathrm{L})$ & $396.5 \pm 10.60^{+}$ & $472 \pm 84.85^{+}$ & $852.5 \pm 24.93^{*}$ & $665.5 \pm 62.93^{*}$ & $373.5 \pm 38.89^{+}$ & $405 \pm 17.9^{+}$ \\
\hline \multicolumn{7}{|c|}{ Kidney indices of toxicity } \\
\hline Total proteins $(\mathrm{mg} / \mathrm{dL})$ & $56.5 \pm 12.02$ & $49.5 \pm 3.53$ & $51.5 \pm 2.12$ & $52.5 \pm 2.12$ & $60 \pm 5.65$ & $60 \pm 4.24$ \\
\hline Urea $(\mathrm{mmol} / \mathrm{L})$ & $0.31 \pm 0.01^{++}$ & $0.37 \pm 0.25^{+}$ & $0.39 \pm 0.4^{* *}$ & $0.41 \pm 0.15^{*}$ & $0.25 \pm 0.9^{*+}$ & $0.27 \pm 0.13^{*+}$ \\
\hline Creatinine $(\mu \mathrm{mol} / \mathrm{L})$ & $5 \pm 1.41$ & $4.5 \pm 0.5$ & $6.5 \pm 0.5$ & $7 \pm 1$ & $6.5 \pm 1.5$ & $5.5 \pm 0.5$ \\
\hline \multicolumn{7}{|c|}{ Plasma mineral element status } \\
\hline $\mathrm{Ca}^{2+}(\mathrm{mmol} / \mathrm{L})$ & $20.5 \pm 0.70^{+}$ & $19 \pm 1.41^{+}$ & $64 \pm 1.41^{*}$ & $86.5 \pm 9.19^{*}$ & $96.5 \pm 2.10^{*+}$ & $82.5 \pm 10.60^{*}$ \\
\hline $\mathrm{Na}^{2+}(\mathrm{mmol} / \mathrm{L})$ & $140.5 \pm 0.70$ & $139.5 \pm 0.70$ & $128.5 \pm 14.84$ & $137.5 \pm 2.13$ & $141.5 \pm 0.70$ & $139 \pm 0.1$ \\
\hline $\mathrm{K}^{+}(\mathrm{mmol} / \mathrm{L})$ & $5.25 \pm 0.05$ & $5.05 \pm 0.025$ & $6.2 \pm 0.3$ & $5.7 \pm 0.1$ & $4.2 \pm 0.1^{*+}$ & $4.7 \pm 0.2^{+}$ \\
\hline $\mathrm{Cl}^{-}(\mathrm{mmol} / \mathrm{L})$ & $97 \pm 2.82$ & $101.5 \pm 0.71$ & $88.5 \pm 2.12$ & $106.5 \pm 2.11$ & $102.5 \pm 0.69$ & $102 \pm 4.24$ \\
\hline
\end{tabular}

${ }^{*} p<0.05$ vs. group $1 .{ }^{+} p<0.05$ vs. group 2 .

calcium level was directly associated with T2D risk [47, 48]. However, the daily coadministration of apple vinegar $(2 \mathrm{~mL} / \mathrm{kg})$ was not able to ameliorate the calcium plasma level. That is probably related to its high concentration in macroelements, especially calcium. In addition, it has a stimulating effect on calcium absorption $[49,50]$. This may improve the reduction of blood pressure by the renin-angiotensin system through the inhibition of renin release [50].

Creatinine is a result of the breakdown of muscle creatine, while urea is a metabolic waste of proteins [51]; the increase of these two renal biomarkers in nontreated diabetic group is a sign of nephropathy diabetic. Weekers and Krzesinski showed that the diabetic nephropathy is due to an alteration of the renal glomeruli owing to glycotoxicity, oxidative stress, and high intraglomerular pressure [52].

In this study, the oral administration of apple vinegar at a dose of $2 \mathrm{~mL} / \mathrm{kg}$ decreased urea levels in both sexes and creatinine in female rats but not significantly. This effect could be due to its phenolic components particularly pyrogallol and catechin [38]. Previous studies reported that catechin and pyrogallol can prevent kidney damage and lower the levels of creatinemia and uricemia $[18,53]$.

\section{Conclusion}

The chemical analysis of apple vinegar revealed the presence of bioactive compounds such as a high content of flavonoids which might be responsible for the exceptional biological properties of apple vinegar in this case the antioxidant activity, the antihyperglycemic activity, and the antihyperlipidemic activity.

Our results show that the hypercaloric diet (D-glucose) is associated with increase in blood sugar, triglycerides, cholesterol, LDL, liver enzyme levels, urea, and creatinine.

The daily intake of vinegar could offer promising protective effects on metabolic changes induced by HCD.

\section{Data Availability}

The data used to support the findings of this study are available from the corresponding author upon request.

\section{Conflicts of Interest}

The authors declare that they have no competing interests.

\section{Authors' Contributions}

All the authors have accepted responsibility for the entire content of this submitted manuscript and approved submission.

\section{References}

[1] B. D. Oomah and G. Mazza, "Functional foods," The Wiley Encyclopedia of Science and Technology, vol. 2, pp. 11761182, 2000. 
[2] J. M. Rippe and T. J. Angelopoulos, "Relationship between added sugars consumption and chronic disease risk factors: current understanding," Nutrients, vol. 8, no. 11, p. 697, 2016.

[3] S. M. Grundy, "Obesity, metabolic syndrome, and cardiovascular disease," The Journal of Clinical Endocrinology and Metabolism, vol. 89, no. 6, pp. 2595-2600, 2004.

[4] K. Marinou, D. Tousoulis, A. S. Antonopoulos, E. Stefanadi, and C. Stefanadis, "Obesity and cardiovascular disease: from pathophysiology to risk stratification," International Journal of Cardiology, vol. 138, no. 1, pp. 3-8, 2010.

[5] P. Singla, A. Bardoloi, and A. A. Parkash, "Metabolic effects of obesity: a review," World Journal of Diabetes, vol. 1, no. 3, pp. 76-88, 2010.

[6] B. M. Popkin, L. S. Adair, and S. W. Ng, "Global nutrition transition and the pandemic of obesity in developing countries," Nutrition Reviews, vol. 70, no. 1, pp. 3-21, 2012.

[7] F. Shahidi and H. Miraliakbari, "Omega-3 (n-3) fatty acids in health and disease: part 1-cardiovascular disease and cancer," Journal of Medicinal Food, vol. 7, no. 4, pp. 387-401, 2004.

[8] G. Zhao, T. D. Etherton, K. R. Martin, S. G. West, P. J. Gillies, and P. M. Kris-Etherton, "Dietary alpha-linolenic acid reduces inflammatory and lipid cardiovascular risk factors in hypercholesterolemic men and women," The Journal of Nutrition, vol. 134, no. 11, pp. 2991-2997, 2004.

[9] A. El Midaoui, Y. Haddad, and R. Couture, "Beneficial effects of argan oil on blood pressure, insulin resistance, and oxidative stress in rat," Nutrition, vol. 32, no. 10, pp. 1132-1137, 2016.

[10] K. Hamden, A. Elfeki, F. Ayadi, K. Jamoussi, and H. Masmoudi, "Therapeutic effect of phytoecdysteroids rich extract from Ajuga iva on alloxan induced diabetic rats liver, kidney and pancreas," BioFactors, vol. 33, no. 3, pp. 165-175, 2008.

[11] A. Shirpoor, B. Ilkhanizadeh, R. Saadatian et al., "Effect of vitamin $\mathrm{E}$ on diabetes-induced changes in small intestine and plasma antioxidant capacity in rat," Journal of Physiology and Biochemistry, vol. 62, no. 3, pp. 171-177, 2006.

[12] G. Park, D. I. P. Paudyal, Y. Park et al., "Effects of pine needle extracts on plasma cholesterol, fibrinolysis and gastrointestinal motility," Biotechnology and Bioprocess Engineering, vol. 13, no. 2, pp. 262-268, 2008.

[13] D. Giugliano, A. Ceriello, and G. Paolisso, "Diabetes mellitus, hypertension, and cardiovascular disease: which role for oxidative stress?," Metabolism, vol. 44, no. 3, pp. 363-368, 1995.

[14] K. F. Shireen, R. D. Pace, M. Mahboob, and A. T. Khan, "Effects of dietary vitamin E, C and soybean oil supplementation on antioxidant enzyme activities in liver and muscles of rats," Food and Chemical Toxicology, vol. 46, no. 10, pp. 3290-3294, 2008.

[15] N. Ogawa, H. Satsu, H. Watanabe et al., "Acetic acid suppresses the increase in disaccharidase activity that occurs during culture of Caco-2 cells," The Journal of Nutrition, vol. 130, no. 3, pp. 507-513, 2000.

[16] C. S. Johnston, S. Quagliano, and S. White, "Vinegar ingestion at mealtime reduced fasting blood glucose concentrations in healthy adults at risk for type 2 diabetes," Journal of Functional Foods, vol. 5, no. 4, pp. 2007-2011, 2013.

[17] P. Mitrou, E. Petsiou, E. Papakonstantinou et al., "Vinegar consumption increases insulin-stimulated glucose uptake by the forearm muscle in humans with type 2 diabetes," Journal of Diabetes Research, vol. 2015, Article ID 175204, 7 pages, 2015.
[18] B. H. Halima, K. Sarra, B. J. Houda, G. Sonia, and A. Abdallah, "Antihyperglycemic, antihyperlipidemic and modulatory effects of apple cider vinegar on digestive enzymes in experimental diabetic rats," International Journal of Pharmacology, vol. 12, no. 5, pp. 505-513, 2016.

[19] C. S. Johnston, C. M. Kim, and A. J. Buller, "Vinegar improves insulin sensitivity to a high-carbohydrate meal in subjects with insulin resistance or type 2 diabetes," Diabetes Care, vol. 27, no. 1, pp. 281-282, 2004.

[20] N. A. A. Omar, M. M. A. Ayat, S. R. Shafik, S. A. Elshweikh, and S. M. E. Sayed, "Apple cider vinegar (a prophetic medicine remedy) protects against nicotine hepatotoxicity: a histopathological and biochemical report," American Journal of Cancer Prevention, vol. 7, 2015.

[21] A. Bouazza, A. Bitam, M. Amiali, A. Bounihi, L. Yargui, and E. A. Koceir, "Effect of fruit vinegars on liver damage and oxidative stress in high-fat-fed rats," Pharmaceutical Biology, vol. 54, no. 2, pp. 260-265, 2015.

[22] M. Naziroğlu, "Apple cider vinegar supplementation modulates lipid peroxidation and glutathione peroxidase values in lens of ovariectomized mice," Cell Membranes and Free Radical Research, vol. 4, no. 3, 2012.

[23] V. L. Singleton, R. Orthofer, and R. M. Lamuela-Raventós, "[14] Analysis of total phenols and other oxidation substrates and antioxidants by means of Folin-Ciocalteu reagent," in Methods in Enzymology, vol. 299 of Oxidants and Antioxidants Part A, , pp. 152-178, Academic Press, 1999.

[24] K. W. Kong, S. Mat-Junit, N. Aminudin, A. Ismail, and A. Abdul-Aziz, "Antioxidant activities and polyphenolics from the shoots of Barringtonia racemosa (L.) Spreng in a polar to apolar medium system," Food Chemistry, vol. 134, no. 1, pp. 324-332, 2012.

[25] G. Zengin, T. Arkan, A. Aktumsek, G. O. Guler, and Y. S. Cakmak, "A study on antioxidant capacities and fatty acid compositions of two Daphne species from Turkey: new sources of antioxidants and essential fatty acids," Journal of Food Biochemistry, vol. 37, no. 6, pp. 646-653, 2013.

[26] M. da Graça Miguel, O. Doughmi, S. Aazza, D. Antunes, and B. Lyoussi, "Antioxidant, anti-inflammatory and acetylcholinesterase inhibitory activities of propolis from different regions of Morocco," Food Science and Biotechnology, vol. 23, no. 1, pp. 313-322, 2014.

[27] H. Laaroussi, T. Bouddine, M. Bakour, D. Ousaaid, and B. Lyoussi, "Physicochemical properties, mineral content, antioxidant activities, and microbiological quality of Bupleurum spinosum Gouan honey from the middle atlas in Morocco," Journal of Food Quality, vol. 2020, Article ID 7609454, 12 pages, 2020.

[28] NF V05-118- Janvier, 1974, https://www.boutique.afnor.org/ norme/nf-v05-118/fruits-legumes-et-produits-derivesdetermination-de-la-teneur-en-acidite-volatile/article/ 709410/fa009245.

[29] C. Heikefelt, "Chemical and sensory analyses of juice, cider and vinegar produced from different apple cultivars," Plant Breeding and Biotechnology, vol. 63, 2011.

[30] S. Basu, P. Yoffe, N. Hills, and R. H. Lustig, "The relationship of sugar to population-level diabetes prevalence: an econometric analysis of repeated cross-sectional data," PLoS One, vol. 8, no. 2, article e57873, 2013.

[31] J. L. Sievenpiper, L. Tappy, and F. Brouns, "Fructose as a driver of diabetes: an incomplete view of the evidence," Mayo Clinic Proceedings, vol. 90, no. 7, pp. 984-988, 2015. 
[32] R. J. Perry, L. Peng, G. W. Cline et al., "Mechanisms by which a very-low-calorie diet reverses hyperglycemia in a rat model of type 2 diabetes," Cell Metabolism, vol. 27, no. 1, pp. 210217.e3, 2018.

[33] K. Ebihara and A. Nakajima, "Effect of acetic acid and vinegar on blood glucose and insulin responses to orally administered sucrose and starch," Agricultural and Biological Chemistry, vol. 52, no. 5, pp. 1311-1312, 1988.

[34] H. Liljeberg and I. Björck, "Delayed gastric emptying rate may explain improved glycaemia in healthy subjects to a starchy meal with added vinegar," European Journal of Clinical Nutrition, vol. 52, no. 5, pp. 368-371, 1998.

[35] C. S. Johnston and A. J. Buller, "Vinegar and peanut products as complementary foods to reduce postprandial glycemia," Journal of the American Dietetic Association, vol. 105, no. 12, pp. 1939-1942, 2005.

[36] T. Fushimi and Y. Sato, "Effect of acetic acid feeding on the circadian changes in glycogen and metabolites of glucose and lipid in liver and skeletal muscle of rats," The British Journal of Nutrition, vol. 94, no. 5, pp. 714-719, 2005.

[37] M. Setorki, S. Asgary, A. Eidi, A. rohani, and M. KHazaei, "Acute effects of vinegar intake on some biochemical risk factors of atherosclerosis in hypercholesterolemic rabbits," Lipids in Health and Disease, vol. 9, no. 1, p. 10, 2010.

[38] S. S. Soltan and M. Shehata, "Antidiabetic and hypocholesrolemic effect of different types of vinegar in rats," Life Science Journal, vol. 9, no. 4, pp. 2141-2151, 2012.

[39] S. Bakir, G. Toydemir, D. Boyacioglu, J. Beekwilder, and E. Capanoglu, "Fruit antioxidants during vinegar processing: changes in content and in vitro bio-accessibility," International Journal of Molecular Sciences, vol. 17, no. 10, p. 1658, 2016.

[40] I. Ozturk, O. Caliskan, F. Tornuk et al., "Antioxidant, antimicrobial, mineral, volatile, physicochemical and microbiological characteristics of traditional home-made Turkish vinegars," LWT - Food Science and Technology, vol. 63, no. 1, pp. 144151, 2015.

[41] L. Solieri and P. Giudici, Vinegars of the World, Springer, 2009.

[42] M. Goboza, Y. G. Aboua, N. Chegou, and O. O. Oguntibeju, "Vindoline effectively ameliorated diabetes-induced hepatotoxicity by docking oxidative stress, inflammation and hypertriglyceridemia in type 2 diabetes-induced male Wistar rats," Biomedicine \& Pharmacotherapy, vol. 112, p. 108638, 2019.

[43] M. Bakour, N. Soulo, N. Hammas et al., "The antioxidant content and protective effect of argan oil and Syzygium aromaticum essential oil in hydrogen peroxide-induced biochemical and histological changes," International Journal of Molecular Sciences, vol. 19, no. 2, p. 610, 2018.

[44] N. E. Mohamad, S. K. Yeap, K. L. Lim et al., "Antioxidant effects of pineapple vinegar in reversing of paracetamolinduced liver damage in mice," Chinese Medicine, vol. 10, no. 1, p. 3, 2015.

[45] S. M. Shahid and T. Mahboob, "Diabetes and hypertension: role of electrolytes and Na-K-ATPase," Sciences, vol. 6, no. 23, pp. 1971-1975, 2003.

[46] X. J. Zhue, Z. Laszik, T. Nadasty, V. D. D’Agati, and F. G. Silva, Diagnostic Renal Pathology, Cambridge University Press, New York, 2009.

[47] N. Becerra-Tomás, R. Estruch, M. Bulló et al., "Increased serum calcium levels and risk of type 2 diabetes in individuals at high cardiovascular risk," Diabetes Care, vol. 37, no. 11, pp. 3084-3091, 2014.

[48] J. Zhu, P. Xun, J. C. Bae et al., "Circulating calcium levels and the risk of type 2 diabetes: a systematic review and meta-analysis," The British Journal of Nutrition, vol. 122, no. 4, pp. 376387, 2019.

[49] A. Akpinar-Bayizit, M. A. Turan, L. Yilmaz-Ersan, and N. Taban, "Inductively coupled plasma optical-emission spectroscopy determination of major and minor elements in vinegar," Notulae Botanicae Horti Agrobotanici Cluj-Napoca, vol. 38, no. 3, pp. 64-68, 2010.

[50] S. Kondo, K. Tayama, Y. Tsukamoto, K. Ikeda, and Y. Yamori, "Antihypertensive effects of acetic acid and vinegar on spontaneously hypertensive rats," Bioscience, Biotechnology, and Biochemistry, vol. 65, no. 12, pp. 2690-2694, 2014.

[51] N. Baum, C. C. Dichoso, and C. E. Carlton Jr., "Blood urea nitrogen and serum creatinine: physiology and interpretations," Urology, vol. 5, no. 5, pp. 583-588, 1975.

[52] L. Weekers and J.-M. Krzesinski, "Diabetic nephropathy," Revue Medicale de Liege, vol. 60, no. 5-6, pp. 479-486, 2005.

[53] O. Wongmekiat, W. Peerapanyasut, and A. Kobroob, "Catechin supplementation prevents kidney damage in rats repeatedly exposed to cadmium through mitochondrial protection," Naunyn-Schmiedeberg's Archives of Pharmacology, vol. 391, no. 4, pp. 385-394, 2018. 